\title{
Why in earth? Dustbathing behaviour in jungle and domestic fowl reviewed from a Tinbergian and animal welfare perspective
}

\author{
Olsson IAS and Keeling L. \\ in Applied Animal Behaviour Science 2005, vol. 93 (3-4) pag. 259-282 \\ http://dx.doi.org/10.1016/j.applanim.2004.11.018
}

\section{ABSTRACT}

Dustbathing has been the subject of much research in captive birds. In the present review we bring together the studies of domestic fowl (Gallus gallus domesticus) and jungle fowl (Gallus gallus) to provide a more complete picture of the behaviour. Dustbathing is discussed from the four aspects suggested by Tinbergen (1963): ontogeny, phylogeny, function and causation and a general aim is to give as complete review as possible of research on dustbathing behaviour.

Studies of ontogeny of dustbathing show that early substrate experience affects later preferences. It appears nevertheless as though the behaviour develops more or less normally even in the absence of appropriate dustbathing stimuli. The behaviour itself is described for a number of species, and there are experimental studies of dustbathing in both jungle fowl and domestic fowl, but there is little comparative research which could provide hypotheses about the phylogeny of the behaviour. Similarly, despite extensive discussions about the function of dustbathing behaviour and the many suggestions regarding the survival value of performing the behaviour, few studies have actually addressed this question. It has been demonstrated that dustbathing reduces the amount of feather lipids, thereby increasing the insulation capacity of the plumage, but other suggested functions, such as control of ectoparasites, have not been tested experimentally.

The majority of studies of dustbathing behaviour address the question of causation. Dustbathing shows a clear diurnal rhythm and under unrestricted conditions, hens dustbathe about every two days. Birds deprived of litter show a rebound in dustbathing behaviour when litter is again made available, suggesting an increase in motivation after deprivation and so an influence of internal factors With respect to external factors, it has long been believed that dustbathing is socially facilitated, but this has been questioned in recent studies. The presence of a suitable substrate is an important stimulus for eliciting dustbathing, and hens seem to prefer substrates with a fine structure such as sand and peat. Dustbathing is further increased if the substrate is combined with light and heat. The question of whether or not hens are motivated to dustbathe has important consequences for bird welfare in commercial housing systems, but motivational studies give somewhat conflicting evidence. In the final part of this review, both normal litter dustbathing and 'sham' dustbathing in the absence of litter are discussed from a welfare perspective. 


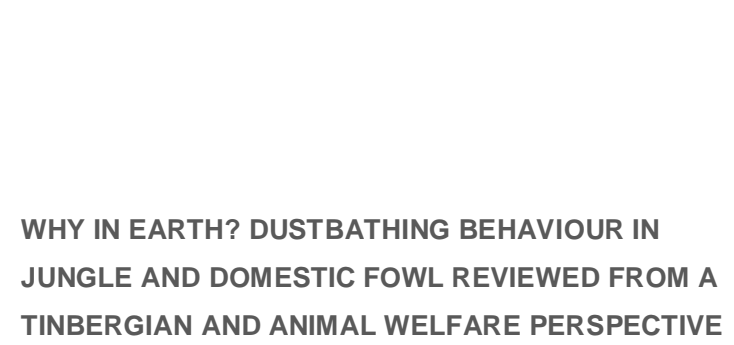

I. ANNA S. OLSSON ${ }^{1} \&$ LINDA J. KEELING

Department of Animal Environment and Health, Swedish University of Agricultural Sciences, P.O. Box 234, SE-532 23 Skara, Sweden.

${ }^{1}$ Present address: Institute for Molecular and Cell Biology, Porto, Portugal.

Correspondent author:

Anna Olsson

Institute for Molecular and Cell Biology

Rua Campo Alegre 823

4150-180 Porto

Portugal.

E-mail: olsson@ibmc.up.pt

Telephone: +351226074900

Fax: +35122609 9157

\section{Introduction}

Dustbathing is a complex and conspicuous behaviour performed by both jungle fowl and domestic fowl and has been the subject of many studies in birds of these different subspecies under captive conditions. The dustbathing behaviour sequence contains a number of elements which have been described in detail both for junglefowl (Gallus gallus; Kruijt, 1964) and domestic fowl (Gallus gallus domesticus; van Liere, 1991). The dustbathing sequence starts with the bird scratching and bill raking in the substrate. Gradually, it erects its feathers and squats down in the substrate. The part of the sequence that occurs when the bird is lying down contain four main elements: vertical wing-shaking, head rubbing, bill-raking and scratching with one leg (van Liere, 1991). This vigorous phase of dustbathing is followed by a phase during which the feathers are flattened against the body and the bird spends most time side-lying or side-rubbing, although interrupted with some of the elements from the first phase. About 20 minutes after the first vertical wing-shake, the bird stands up and shakes the dust out of its plumage and moves to other activities (van Liere, 1991). It is suggested that dustbathing functions to remove parasites and excess feather lipids and to generally keep the plumage in good condition. Under conditions with unrestricted access to litter, adult birds dustbathe about every other day (Vestergaard, 1982). When birds have no access to suitable litter material they sham dustbathe, i. e. they go through the sequence of dustbathing behaviour but on the bare floor (e.g.

Vestergaard, 1981a, b).

Dustbathing behaviour has received much research attention during the past decades, mainly because of its suggested importance for animal welfare. The battery cage for laying hens has become a symbol for the restrictive housing in intensive animal production, and sham dustbathing in caged hens is one of the most striking examples of an abnormal behaviour pattern in such systems. The fact that hens in battery cages perform dustbathing behaviour without litter has been taken to indicate that hens are highly motivated to dustbathe and that their welfare is compromised in housing systems where dustbathing material is not provided. This view is reflected in recent changes in animal welfare legislation in the European Union, according to which from 2012 all laying hens must be housed with access to litter.

Despite the increasing body of existing information, dustbathing has not been the subject of a review since 1992 (van Liere, 1992). Since then, a considerable number of studies have approached dustbathing behaviour, its ontogeny and the various factors affecting dustbathing motivation. With the changes in legislation, cages equipped with dustbaths, perches and nests (so called furnished 


\section{N:I:IBMC}

cages) have been introduced in several countries, leading

to renewed interest in this subject Recent research for

example shows that hens housed in furnished cages perform sham dustbathing behaviour on the wire floor despite having access to a dustbath (Lindberg \& Nicol,

1997; Olsson \& Keeling, 2002), indicating that there are still central questions left to answer about dustbathing behaviour and animal welfare. Before advancing with further research, it is important to review present knowledge and to recognise that a complete understanding of the behaviour cannot come from considering only the welfare point of view. In his influential paper summarizing 30 years of ethology research, Tinbergen (1963) advocated that students of ethology, as well as of other disciplines of biology, ought to consider four major questions: causation, survival value (later termed 'function'), evolution (later often referred to as 'phylogeny') and ontogeny. We believe that this remains a valid approach nearly 40 years after the original paper was published and therefore decided to use the Tinbergen questions as the basis for this review of dustbathing behaviour. In the end of the review we extend the discussion related to dustbathing motivation in different situations. We address the different animal welfare aspects of the way hens are housed, and take sham dustbathing in furnished cages as an example.

\section{Ontogeny}

"All concerned agree that a complete understanding of behaviour requires an understanding of its ontogeny, just as morphologists agree that it is not sufficient to understand the adult form, but also the way in which this develops during ontogeny. ---I should like to characterise the phenomenon as "change of behaviour machinery during development". This is not, of course, the same as a change of behaviour during development; when in spring we see a thrush pick up and smash a snail for the first time in months, this change in feeding behaviour may be due to snails having reappeared for the first time after winter. We can conclude that the thrush itself, i.e. its behaviour machinery, has changed only if the behaviour change occurred while the environment was kept "(Tinbergen, 1963)

The study of ontogeny, which Tinbergen (1963) pointed out is essential for understanding of a behaviour system, is the study of how behaviour develops in an individual through the integration of innate and learned features of the behaviour. In this section we review work on how dustbathing normally develops in the young chick, which aspects of the development occur independently of the environment and how the type of substrate affects development.

Normal development of different components of the behaviour

Kruijt (1964) was the first to describe the ontogeny of dustbathing behaviour in junglefowl and the topic has been the subject of a further series of studies carried out by Klaus Vestergaard, Jerry Hogan and co-workers. Some of this work is reviewed in Hogan's (1994) synthesis of the development of behavioural systems. The different elements of dustbathing appear separately in the developing junglefowl chick, with bill-raking seen as early as day 2 and the other elements appearing gradually until the day 10-12 after hatching (Kruijt, 1964). Very little dustbathing behaviour is seen in junglefowl during the first week after hatching, but the behaviour increases rapidly during the second week until it stabilizes at week 4 (Hogan et al., 1991). An effect of deprivation is present as early as day 8 , in that birds compensate for a longer delay of first access to dust by more dustbathing (Hogan et al., 1991). A diurnal rhythm with a peak in the middle of the day was found as early as at 14 days of age and, although less accentuated in young birds, the dustbathing activity becomes more concentrated around the daily peak as the birds grow older (Hogan \& Van Boxel, 1994). When adult birds have free access to litter, the peak in dustbathing behaviour is about 6 hours after lights-on (Vestergaard, 1982; Hogan \& Van Boxel, 1993). Dustbathing frequency appears to reach a maximum at age 2-3 weeks, when birds dustbathe 2-3 times a day, thereafter decreasing to the adult average frequency of dustbathing every two days

Version: Postprint (identical content as published paper)

This is a self-archived document from Instituto de Biologia Molecular and Celular in the University of Porto Open Repository For Open Access to more of our publications, please visit http://repositorio-aberto.up.pt/handle/10216/26153 


\section{N:I:IBMC}

(Hogan \& Van Boxel, 1994). The authors attributed this decrease in frequency to an increase in the general level of the threshold releasing dustbathing; however it should be remembered that young birds moult and that the increased frequency of dustbathing may also be associated with the loss and replacement of plumage.

Effect of environment on the development of the behaviour In the developing chick, dustbathing behaviour appears independently of experience of a substrate (Kruijt, 1964), and some evidence even suggests that it may develop normally in the absence of a substrate. For example, when junglefowl chicks were reared either with access to sand and grass sod or on a wire floor, it was found that 2-3 months old birds performed essentially the same dustbathing behaviour, irrespective of whether or not they had access to dustbathing material (Vestergaard et al., 1990). Petherick et al. (1995) also found that the amount of sham dustbathing behaviour during a period of litter deprivation did not differ between pullets reared with access to peat moss and pullets reared on a wire floor. That feedback from the feathers is not necessary is also demonstrated in work showing that dustbathing seems to develop normally in featherless chicks (Vestergaard et al., 1999). Chicks of a mutant featherless line were kept on a wire floor and given 1-h daily access to sand. In the same way as previously reported for normal chicks (Hogan et al., 1991), deprivation resulted in increased dustbathing behaviour at the second week of life. Moreover, when a dustbathing bout was interrupted by the experimenter, the birds compensated by dustbathing more next time they were given access to sand.

Although from the section above it appears that dustbathing can develop in the absence of litter, early experience of substrate does have an effect on the behaviour. In the previously mentioned experiment with sand-reared and wire-reared birds, Vestergaard et al. (1990) found that rearing affected birds' choice of substrate at the age of 6-9 months. Birds reared and housed with access to sand and grass sod directed all dustbathing activity towards the sand or soil, whereas birds reared and housed on wire, bill-raked the feed and also directed bill-raking and scratching towards the plumage of other birds. Although Vestergaard et al. (1990) found that the amount of dustbathing was unaffected, two experiments report less dustbathing in birds reared without litter than in litter-reared birds. NorgaardNielsen (1997) found that wire-reared domestic fowl dustbathed less than sand-reared birds during the first month of life (however, there was no difference in measures taken after day 18). Whether or not birds had access to litter during their first four weeks of life also affected the amount of dustbathing as adults, in that birds reared without litter performed fewer dustbathing events than birds reared with straw or sand (Johnsen et al., 1998). Substrate access further affects the structure of the behaviour, as demonstrate by Larsen et al. (2000). Chicks were reared on wire or on sand and observed during dustbathing for three phases of development: 1) Days 2-5, 2) Days 8-15 and 3) Days 20-23. During both phase 1 and phase 3, dustbathing bouts were shorter for birds kept on wire. The dustbathing sequence was also affected, in that wire-kept chicks did not show siderubbing and that pecking (including allopecking) replaced bill raking in phase 3 . The authors suggest that such allopecking becomes incorporated into the dustbathing sequence in wire-reared birds and may develop into featherpecking.

The effect of substrate on dustbathing was investigated by Vestergaard and co-workers in three experiments in which chicks were trained with different substrates by giving them repeated training sessions during their first weeks of life. Vestergaard and Hogan (1992) reared junglefowl chicks either with access to sand for pecking (but not dustbathing) or on wire floor only and gave all chicks 1-h access to one of three substrates (black sand (1-1.5 mm particles), white sand (0.2-0.3 mm particles) or feathers) for dustbathing repeatedly from day 4 to day 29 . Access to sand for pecking had no effect, but which substrate birds were allowed to dustbathe in affected their dustbathing behaviour. Almost all birds trained on black sand learned to dustbathe on this substrate, whereas many birds on white sand and the majority of birds on feathers did not dustbathe on the substrate, but instead sham dustbathed on the wire floor in 


\section{FI:-1BMC}

their home cages. Sanotra et al. (1995) trained domestic

chicks in a similar way by presenting them either straw, wood-shavings or feathers and found no effect of substrate on dustbathing during training. When substrate preference was tested by presenting the chicks simultaneously with two substrates: the one on which they had been trained in as well as sand, the use of the training substrate gradually decreased as birds increasingly dustbathed in sand over repeated tests. This was accompanied by an increase in latency to start dustbathing in birds. Also Vestergaard and Lisborg (1993) found a gradual transfer of preferred substrate when they trained domestic chicks either on sand or on feathers. When the birds were given a choice between feathers and sand as a dustbathing substrate, sand-trained birds did all their dustbathing in sand but feather-trained chicks initially dustbathed most in feathers. Over three repeated choice test sessions, dustbathing in feathers was gradually replaced by dustbathing in sand, again accompanied by an increased latency to start dustbathing in feather-trained chicks. The authors suggested that as long as birds have no other experience, they become imprinted on a stimulus (such as feathers) even if this is not appropriate for dustbathing. When presented with a supposedly more appropriate substrate along with the original substrate, the birds may have difficulty in identifying a dustbathing substrate; hence the longer latency.

That the response to a dusty stimulus may be to some extent innate was suggested by Petherick et al. (1995). Chicks were reared until 8 weeks of age either on a wire floor or with access to peat. When these birds were later presented with a tray of peat below the floor in their home cage, almost all birds dustbathed, irrespective of rearing condition. Nevertheless, there was an effect of rearing when the peat was presented either in the cage or in front of the cage. Peat-reared birds dustbathed almost always when they saw peat, no matter whether it was in the cage, below it or in front of it. Wire-reared birds, on the other hand, dustbathed almost only when the peat was presented below the cage. A possible explanation of the finding is that dustbathing in the wire-reared birds may have become coupled to the presence of dust and droppings below the cage, which had previously acted as the dusty stimulus eliciting dustbathing behaviour. This would be consistent with the findings that hens in cages sham dustbathe near the feed trough possibly treating the feed as a dustbathing stimulus (Lindberg \& Nicol, 1997). No such feed stimulus was available in the experiment by Petherick et al. (1995), since the feed was pelleted and presented in closed feeders.

In summary, dustbathing behaviour develops irrespective of whether or not birds have access to a substrate and even birds reared entirely on wire respond to a dusty substrate when it is presented to them later in life. However, there are indications that both the amount of dustbathing, the structure of the dustbathing sequence and the ability to identify a substrate are negatively affected if birds are reared without litter.

\section{Phylogeny}

"Evolutionary study has, of course, two major aims: the elucidation of the course evolution must be assumed to have taken, and the unravelling of its dynamics. The first task is being pursued mainly through comparison of groups of closely related species.--- The work on evolution dynamics can be said to consist of two major parts. First, the genetic control of species-specific behaviour, about which we know so much less than about that of speciesspecific structure, is now being studied with all the methods available in genetics; differences between species, subspecies and strains raised in identical environments are registered; the effect of mutations on behaviour are beginning to be explored, and controlled cross-breeding is being done. --- The second major task is the study of the influence of selection on behaviour evolution. This task is being tackled in two different ways. One is the study of survival value of species-specific characters, the other is the direct application of a controlled selection pressure and its results over series of generations" (Tinbergen, 1963). 


\section{FI:-IBMC}

Of the different methods pointed out by Tinbergen (1963), dustbathing research with a phylogenetic approach is dominated by studies of genetic control of the behaviour. Observational and experimental studies have described the behaviour for several species but no comparative analyses have been carried out.

Dustbathing in different species

While water is the most common substrate for bathing, certain species show dustbathing behaviour. Many species bathe both in water and in dust, but gallinaceous birds will only dustbathe (Simmons, 1964). Experimental studies of dustbathing in galliform birds include different species of quail; Bobwhite quail (Colinus virginianus) (e.g. Brett \& Kruse, 1967; Borchelt et al., 1973; Borchelt \& Overman, 1975) and Japanese quail (Coturnix coturnix japonica) (e.g. Gerken \& Petersen, 1987; Gerken et al., 1988) as well as fowl (this review). The behaviour is also described for African ostrich (Struthio-camelis) (Sambraus, 1994), turkey (Sherwin \& Kelland, 1998) and peacock (personal observation). However, there seems to be remarkably little work which would allow a proper analysis of phylogeny.

Similarly to that reported for fowl (this review), dustbathing development in quail is affected by age (Brett \& Kruse, 1967) and dust experience (Borchelt \& Overman, 1975), and dustbathing activity by previous dust deprivation (Borchelt et al., 1973). In fowl, dustbathing has been studied both in domestic fowl (Gallus gallus domesticus) and in Burmese Red Junglefowl (Gallus gallus spadiceus), as can be seen in the large number of studies included in this review. In domestic fowl, the behaviour is described both for laying strains and for meat-type birds. There is no evidence indicating substantial differences, although we know of no study comparing the dustbathing behaviour of different sub-species of fowl.

Genetic influence on dustbathing

A genetic effect on dustbathing behaviour in Japanese quail was suggested by Gerken and Petersen (1987). They selected birds into 'bathers' and 'non-bathers' on the basis of their dustbathing activity (measured as number of vertical wingshakes when dustbathing on litter) and bred the two lines for 9 generations. The selected breeding resulted in a significantly divergent response, with the line of non-bathers showing decreasing dustbathing activity and the line of bathers increasing dustbathing over the 9 generations of selection. In a later experiment, Gerken et al. (1988) found that birds selected for low dustbathing activity were also more fearful in tests and suggested that the selection for dustbathing activity had also resulted in a change in fearfulness. However, we suggest that the cause-effect relationship may be the reverse. While engaged in dustbathing, birds are vulnerable to attacks from predators; hence birds are not likely to start a dustbathing bout in a situation in which they do not feel secure. In a novel situation such as the testing situation used by Gerken and Petersen (1987) to characterize birds (birds reared without litter, tested individually and with only two days prior experience of the dustbathing substrate), it would be expected that the more fearful a bird is, the less it would dustbathe. Thus we feel it cannot be excluded that Gerken and coworkers may have selected for level of fearfulness rather than level of dustbathing activity.

\section{Function}

"I have always been amazed, and I must admit annoyed as well, when I met, among fellow-zoologists, with the implied or stated opinion that the study of survival value must necessarily be guesswork, and that exact experimentation on the problem is in principle not possible. I am convinced that this is due to a confusion of the study of natural selection with that of survival value. While I agree that the selection pressures which must be assumed to have moulded a species' past evolution can never be subjected to experimental proof, and must be traced indirectly, I think we have to keep emphasising that the survival value of the attributes of present-day species is just as much open to experimental inquiry as is the causation of behaviour or any other life process." (Tinbergen, 1963) 


\section{N:I:IBMC}

Tinbergen (1963) used the term 'survival value' for what has become to be termed 'function'. He referred to Konrad Lorenz's definition of a behaviour pattern as comparable to an organ in being a complex system which forms part of the characteristics of the animal. Only by taking this approach did it become possible to ask how a certain behaviour pattern contributes to the survival of the organism, in the same way as questions about function can be asked for an organ (Tinbergen, 1963). In this section we discuss the suggested function of dustbathing in terms of plumage condition. Dustbathing behaviour involves passing a substrate through the feathers and it is believed that its function is to help to keep the plumage in good condition and in particular remove stale feather lipids.

When birds were deprived of litter for 32 days, the amount of feather lipids increased and the feathers became less fluffy, whereas feather lipid levels returned to normal as soon as the birds were given access to litter again (van Liere \& Bokma, 1991). When comparing birds housed in a battery cage system with birds from a perchery with litter floor, Sandilands et al (2004) also found a much higher lipid concentration in birds that had no access to litter. However, not all dustbathing substrates are equally efficient in removing feather lipids. Van Liere (1991) found that birds housed with woodshavings as a dustbathing substrate had higher levels of feather lipids on the proximal plumulous parts of the feathers than birds housed with access to sand. The author suggested that this may reflect that woodshavings do not penetrate the plumage to reach the proximal part of the feathers. When birds were housed on either peat, sand or wood-shavings, van Liere \& Siard (1991) found differences in down height, amount of feather lipids and exterior temperature on the back. Birds housed on peat had the fluffiest feathers, least feather lipids and lowest back temperature (reflecting the insulation capacity of the plumage), followed by birds on sand and finally birds on wood-shavings.

Finally, it has been suggested that dustbathing may be effective in controlling ectoparasites by removing the feather lipids they feed on (see Borchelt \& Duncan, 1974).
The process of dustbathing itself may also dislodge parasites, and the pecking other birds often direct at dustbathing companions may actually be directed at ectoparasites in the plumage rather than at the feathers themselves. However, we have not found any experimental evidence for an effect of dustbathing on parasite control.

In summary, the possibility to dustbathe improves plumage condition in several aspects, with substrates made up of smaller particles (e.g. sand or peat) being more efficient than more course substrates. Other suggested functions, such as control of ectoparasites, have not been experimentally tested.

\section{Causation}

"As far as the study of causation of behaviour is concerned the boundaries between these fields [ethology, neurophysiology and physiological psychology] are disappearing, and we are moving fast towards one Physiology of Behaviour, ranging from behaviour of the individual and even of supra-individual societies all the way down to Molecular Biology." (Tinbergen, 1963).

With the development of ethology as the study of animal behaviour within a biological framework, behavioural systems were recognised as complex integrations of different mechanisms rather than simple responses to simple stimuli. Recognising this sparked interest in studying causation, which Tinbergen (1963) saw as a way of approaching the discipline of ethology to that of physiology. Nevertheless, although causation can be traced back to physiological mechanisms, many questions about the effect of internal and external stimuli can be addressed without entering into the neurophysiological background of behaviours, as the reviewed studies show. Since it is this question that has been the focus of most attention in studies of dustbathing, we have divided the work on causation into parts dealing with external physical stimuli, social stimuli and effect of deprivation. Finally, we discuss two previously presented models of dustbathing behaviour. 


\section{:I: IBMC}

Effect of external physical stimuli

\section{Substrate preference}

The presence of a suitable substrate is the most obvious of the external stimuli which affect dustbathing behaviour. Overall, substrates with a fine structure, such as sand and peat, are preferred over substrates consisting of larger particles, such as straw and wood-shavings. Petherick and Duncan (1989) reared domestic chicks on wood-shavings and gave them access to four different substrates: peat moss, sand, sawdust and wood-shavings during days 21 42. On days 43-50, the birds' behaviour in the different substrates was studied. It was found that more bouts, and also the greatest total time dustbathing occurred in peat moss than in the other substrates. In fact, it appeared that full dustbathing bouts took place only in peat. When two fine-particle substrates (peat and sand) were compared, Duncan et al. (1998) found no preference: similar numbers of dustbathing events were observed when hens were kept with peat as compared to when kept with sand. Shields et al (2004) found a clear preference for sand as compared to rice hulls, woodshavings and a paper-based bedding material. Broiler chickens both pecked and dustbathed more in sand than in the other substrates, had a shorter latency to enter the sand area and spent more time there, and this preference did not change from week 1 to week 7 . Van Liere and Siard (1991) studied the substrate preference in birds reared without litter and then housed during weeks 18-22 either with sand or wood-shavings or on a wooden slatted floor (without litter). These birds were thereafter presented with three substrates simultaneously; sand, wood-shavings and peat. Initially, most litterexperienced birds dustbathed on the substrate they had previously been housed on, whereas birds with no litter experience dustbathed on sand. Non-experienced and wood-shavings-experienced birds frequently changed substrate over the first 7 days before preferences for peat stabilized, whereas sand-experienced birds continued to dustbathe in sand. Altogether, these findings may support the view that there are only slight differences in suitability between sand and peat as dustbathing substrates, but that previous experience affects preferences. When hens with previous experience of woodshavings or woodshavings and sand were given renewed access to litter after 6 days deprivation, the latency to start dustbathing was the same irrespective of substrate, but dustbathing bouts were longer in wood-shavings than in sand. It was suggested that the prolonged bouts may be a sign that birds do not get the appropriate feedback to end a dustbathing bout in woodshavings, since the substrate does not penetrate the plumage as well as smaller particles do (van Liere 1991).

When young domestic chicks (days 2-13) were presented with feathers, straw and wood-shavings as substrates for dustbathing, they did not show any preference. However, when the alternatives were feathers, straw and sand, a strong preference was indicated by the fact that almost all dustbathing took place in sand. (Sanotra et al., 1995). Peat unfortunately was not included in this study. That neither straw nor feathers seem to be appropriate for dustbathing, was further indicated by the findings that although working for access to them, birds did not dustbathe in these substrates (Gunnarsson et al., 2000). It has been suggested that substrate preference is determined by imprinting during an early sensitive period (Vestergaard \& Lisborg, 1993), and Nicol et al (2001) found that exposure to litter at around day 60 was a factor strongly influencing how much birds aged 211-212 days would dustbathe in the substrate with which they had previous experience.

Matthews et al. (1995) compared the slopes of demand curves for peat, wood shavings and sand. Although the demand was similar when the substrates were used for pecking or scratching, the slope for dustbathing in sand was significantly less than for dustbathing in wood shavings, indicating that birds were more motivated to work for access to sand and less motivated to work for wood-shavings for dustbathing. This again supports the view that dustbathing in wood-shavings may be less rewarding.

\section{Other external stimuli}

Hogan and Van Boxel (1993) showed that birds exposed to a light and heat stimuli for a limited period daily, rescheduled their behaviour so that most dustbathing took place during the hour with extra light and heat. This effect

Version: Postprint (identical content as published paper)

This is a self-archived document from Instituto de Biologia Molecular and Celular in the University of Porto Open Repository For Open Access to more of our publications, please visit http://repositorio-aberto.up.pt/handle/10216/26153 


\section{N:I:IBMC}

did not persist during a subsequent week in the absence of the extra stimuli and so seemed to be a direct effect of the stimuli. Duncan et al. (1998) found that hens dustbathed more when they were exposed to radiant heat or a combination of light and radiant heat than in the control situation with no extra light or heat. Similarly, it was found that the hens dustbathed more at higher ambient temperatures, although the authors suggested this was due to inhibition of dustbathing at low temperatures rather than stimulation at higher.

In summary, the presence of a suitable substrate is an important stimulus for eliciting dustbathing, and hens seem to prefer substrates with a fine structure such as sand and peat. Dustbathing motivation is further increased if the substrate is combined with light and heat.

Effect of social stimuli

Vestergaard (1982) found that birds with free access to litter tended to dustbathe together, and the observation that if one hen starts to dustbathe others will join her has led to the suggestion that the behaviour is socially facilitated (Vestergaard, 1981b). This view has been widespread among poultry ethologists, and Duncan et al. (1998) found support for a social facilitation effect in that individually caged hens dustbathed more when they could see dustbathing stimulus hens than when they could see litter only. However, in two studies where we have directly addressed the question, we have found results suggesting that the effect of social factors in dustbathing may not be mediated through social facilitation but through other types of social influence. In an experiment where hens got access to litter in the presence of a stimulus hen (either dustbathing or performing some other behaviour) we found that stimulus hen behaviour had no effect on the dustbathing behaviour of an observing hen (Olsson et al, 2002b). Lundberg and Keeling (2003) found that high-ranked hens had a shorter latency to dustbathe when shown a dustbathing hen on video than when shown a standing hen on video, but, since the effect was not shown by low-ranked hens, they suggested that this may be explained in terms of social inhibition in which the sight of a standing bird inhibited dustbathing, rather than social facilitation of the behaviour. On the basis of the two experiments mentioned above, we therefore suggest a reinterpretation of the results reported by Duncan et al. (1998). Since the hens were either alone or in the presence of companion hens among which at least one was dustbathing, what was interpreted as social facilitation in the experimental treatment could equally well be explained by a solitary inhibition effect in the control situation.

The effect of deprivation

In one of the first studies of dustbathing motivation, Vestergaard (1982) deprived a group of hens for varying amounts of time (24-101 h) and studied their behaviour when they were given access to litter either in the morning or in the afternoon. The longer the birds had been deprived of litter, the shorter the latency to start dustbathing and the larger the proportion of hens that dustbathed within the first hour after renewed litter access. Similarly, van Liere and Bokma (1991) found that dustbathing frequency in hens given access to litter after 32 days of deprivation was higher than in hens which had continuous access. These findings have been taken as indications that deprivation results in increased dustbathing motivation. However, when studying the effect of deprivation on how much work hens performed for access to litter, Widowski and Duncan (2000) found somewhat contradictory results in that while most hens pushed open heavier doors for access to peat moss when they had previously been deprived of dustbathing, some of the birds opened heavier doors when they were not deprived. A description of Widowski's and Duncan's interpretation of the behaviour is given in the next section dealing with modelling dustbathing behaviour.

The increased dustbathing after a period of litter deprivation has been attributed to a build-up of feather lipids (see van Liere, 1992). But, as reported previously, the same effect of deprivation was found in both intact and uropygial gland extirpated hens (Nørgaard-Nielsen \& Vestergaard, 1981), indicating that other factors than lipid level contribute to an increase in dustbathing motivation.. Moreover, gland extirpated hens actually dustbathed more, and gave the 


\section{IBMC}

impression of a more disorderly plumage than intact hens, suggesting that feather condition may have some direct influence in controlling dustbathing behaviour.

\section{Modelling dustbathing behaviour}

A model for dustbathing motivation has been presented by Hogan and van Boxel (1993), explaining regulation of motivation through the combination of an internal factor and a circadian rhythm. They suggest that the internal factor builds up with time since last dustbathing (Lorenzian psychohydraulic regulation), whereas the circadian rhythm sets the threshold for the behaviour to be initiated.

According to this model, external effects such as light/heat stimulation and the presence of a suitable dustbathing substrate affect only the threshold. This model has been criticised by Duncan et al. (1998) for over-emphasizing internal factors. Widowski and Duncan (2000) suggest that an alternative model should be based on the theory that behaviours are regulated either through negative motivational affective states, which are active in 'need situations'; or positive motivational affective states, operating in 'opportunity situations' (Fraser \& Duncan, 1998). Widowski and Duncan (2000) suggest that their finding that some hens opened heavier doors for litter access when not deprived cannot be explained using the traditional 'needs' model of dustbathing motivation but are more consistent with the 'opportunity' model. This model predicts that given the opportunity, hens will dustbathe and feel pleasure from doing so, but in the absence of external stimuli dustbathing motivation will be low.

The reality probably lies somewhere between the two models, and the relevance of the internal and external factors respectively may reflect an individuals' situation in that specific moment in time. For example, a bird presented with a highly attractive substrate such as fresh unsoiled peat may initiate a dustbathing bout even though it recently dustbathed (Olsson et al, 2002b); in this situation the external stimulus plays a decisive role. On the other hand, as an example of a situation where internal stimuli overrule external, if deprived sufficiently long hens will sham dustbathe on the bare floor (Olsson et al., 2002a).

\section{Dustbathing motivation in different situations}

As we discussed in the previous section, both internal and external factors are involved in the regulation of dustbathing motivation, but the relative importance of the different factors, as well as the overall motivation may vary between different birds and different situations. It has even been suggested that 'out-of-sight' may mean 'out-of-mind' for a hen and so she would not be motivated to dustbathe if she cannot see a dustbathing substrate. In order to investigate this, Petherick et al. (1990) studied whether birds were able to associate a colour cue with the presence of litter in an experiment where a Y-maze gave access to goal boxes with either peat or a wire floor. If birds could see the floor type when they made their choice, most chose peat, but when over subsequent trials the floor type was only indicated by a colour cue, most birds failed to make a consistent choice. When the training method was changed to massed trials (4 repeated trials per day), more birds showed evidence of learning the association, suggesting that hens could possibly form a connection between a cue and dustbathing behaviour. It is possible therefore that hens are motivated to dustbathe even in the absence of a dustbathing substrate.

The method with massed trials was used in a second study, where the effect of motivational state on choice between food and litter was studied (Petherick et al., 1993). Hens were deprived of either food or litter and given a choice between two goal boxes, one containing food and the other litter. More often birds chose food when they were food deprived than litter when litter-deprived. That is to say that more birds made a choice corresponding to their presumed motivational state when food-deprived. This was the case both when the substrate was indirectly indicated by a colour cue and when it was directly visible to them when they made their choice. The authors concluded that hens are only poorly motivated to access litter compared to food, but discussed other factors which may have affected the results. For example, the presence of food may have been such a strong stimulus that it distracted the birds, and it is 


\section{N:I:EMC}

also possible that dustbathing was inhibited since the birds

were tested alone and so litter was devalued as a substrate compared to feed. Finally, access to litter was limited to 5 minutes during the first 3 trials and only after the fourth trial were birds allowed to stay in litter sufficiently long to complete a dustbathing sequence. Interrupting a bout of dustbathing is likely to reduce the value of the litter resource and may even be aversive (Widowski \& Duncan, 2000).

Taking a different approach, Nicol and Guilford (1991) found evidence supporting the hypothesis that hens are motivated to get access to litter even if they cannot see it. Hens were tested in an apparatus with a tunnel (with a bare floor) in which they could explore and it was found that when no litter was present, litter-deprived hens spent more time exploring in the tunnel than non-deprived birds.

Present evidence is thus not conclusive as concerns whether or not hens are motivated to dustbathe in the absence of litter; however knowing this is crucial for conclusions about animal welfare. Restricting a behaviour will most likely affect welfare if the motivation arises mainly from internal factors, if motivation remains high when the behaviour cannot be performed and if motivation is reduced by performing the behaviour rather than achieving the consequences (Petherick \& Rushen, 1997). Thus, it is the balance between internal and external control of dustbathing that is particularly relevant from an animal welfare point of view.

\section{Animal welfare aspects}

The relationship between dustbathing and bird welfare can be considered in two ways: Firstly, the importance of performing the behaviour per se and thus the direct effect on welfare if the behaviour is thwarted, and, secondly, the possible secondary consequences of not being able to dustbathe, such as deterioration of the plumage, and the effects that these may have on welfare.

How important is dustbathing?

The use of operant studies in animal welfare has been strongly advocated as a tool for understanding which behaviours are important for animals (Dawkins, 1990; 1998). Dustbathing has been the subject of a number of operant studies, but there is not always agreement and results are sometimes difficult to interpret. Whereas some experiments indicate that hens are motivated to work for the possibility to dustbathe, others have failed to show such a motivation. This section is divided up into those studies that show no or doubtful indications of a dustbathing motivation, those studies which indicate a motivation to dustbathe, and finally a discussion of possible explanations for these contradictory findings.

No or doubtful indications of a dustbathing motivation In one of the first studies investigating a possible dustbathing motivation in hens, Dawkins and Beardsley (1986) performed four experiments in which hens had to perform an operant response in order to get access to litter. Two experiments in which pecking a key gave access to litter (sand + sawdust + wood-shavings) did not show that hens were prepared to work more for access to litter than for access to a goal box with a bare wooden floor.

Nevertheless, when the hens could see the substrate (rather than having to rely on a cue) and no response was required, the birds showed a clear preference for litter. Moreover, when the response was changed from keypecking to breaking a photo beam, hens worked for access to litter. This lead Dawkins and Beardsley to attribute their initial finding - that under some conditions hens would not work for access to litter - to an inability to associate dustbathing and litter access with the key-pecking response.

Lagadic and Faure (1987) showed that hens would work by key-pecking for increasing cage size, both when the additional floor was wire-mesh and when it was covered with wood-shavings. The hens also appeared to distinguish between the substrates, as their behaviour differed between substrate and more dustbathing and pecking was seen on litter. In terms of amount of key pecking (size of response), however, the only difference was that a higher proportion of pecks were directed towards the effective key when the reward was a litter-covered floor. The absolute number of 


\section{I:E: IBMC}

pecks (total or specifically at the effective key) did not differ, leading the authors to suggest that hens distinguished between the substrates but were not more motivated to gain access to an increased space with litter than they were to gain access to increased space only. These findings were corroborated in two later experiments. Faure (1991) tested hens from both battery cages and floor pens in the same key-pecking apparatus as used by Lagadic and Faure (1987) and found that irrespective of original housing system hens did not work more for space with litter than for space only. Faure and Lagadic (1994) tested hens in an apparatus where hens could get access to litter without having to peck a key, but at the cost of being exposed to a fan blowing air at different speeds. The hens spent more time on sand than on wire mesh, but the elasticity of demand (defined as change in time spent on substrate as a function of increasing wind speed) did not differ between sand and wire floor.

Although not using any operant technique, Dawkins (1983) also measured the hens' demand for litter against their demand for food in two experiments where hens had to choose between food and litter. When food was available in a wire floor cage and litter (but no food) in an adjacent cage, hens chose litter only when they were not food deprived. Dawkins (1983) then restricted daylight duration so that hens would have to compress different activities in less time than they would normally be active, and found that in this situation hens' motivation (as measured as the number of times they left the wire floor cage with food) to enter the litter floor cage was not greater than their motivation to enter another wire floor cage, all in all indicating that hens found food much more important than litter.

\section{Studies indicating a motivation to dustbathe}

Although not strictly an operant study, Dawkins (1981) reports results which could be interpreted as support for the idea that hens are prepared to pay a certain cost for access to litter. Birds would choose a cage with litter floor (wood shavings and peat) over a wire floor cage, even when the litter floor cage was considerably smaller than the wire floor cage and indeed so small that the bird could hardly move in it. Since birds would choose a larger cage over a smaller when the flooring was the same, these results could be seen as the birds paying a price in terms of space lost in order to gain access to litter. Matthews and co-workers carried out a series of experiments using an apparatus where pecking a key would cause the holding cage with the hen in to move to different floor types, and showed that hens work for peat as well as sand and wood shavings and that they use the substrates for dustbathing (Matthews et al., 1993; 1995). Widowski and Duncan (2000) found considerable individual variation when studying dustbathing motivation with the push-door, an operant technique. Most hens pushed more weight to open the door for access to peat moss when they had previously been deprived of dustbathing, and they also tended to start dustbathing more quickly and dustbathed at a higher proportion of trials. Nevertheless, some of the hens pushed open heavier doors when they were not deprived, and hens also opened the door without subsequently dustbathing. Thus, the authors did not find conclusive evidence for hens' willingness to work for the possibility to dustbathe.

\section{Possible explanations for contradictory results of these studies}

Widowski and Duncan (2000) proposed that whether or not hens can see the substrate is the main difference between studies indicating that hens are highly motivated to dustbathe and those indicating that dustbathing is not very important. However, there are other factors which may have influenced the results. The limited time access to litter is a potential problem in these operant experiments (see Widowski \& Duncan, 2000), since hens need considerable time to perform a complete sequence of dustbathing. Besides devaluing the dustbathing behaviour as compared to when able to finish a bout, interrupting may even be aversive to the hens. On the other hand, as demonstrated by Matthews and co-workers (1993; 1995) 5 minutes access to an area with litter was sufficiently rewarding for hens to work for it in a key-pecking apparatus, and Matthews et al. (1998) have later shown that hens will work for litter access as short as 150 seconds. The experimental 


\section{N:E:IBMC}

set-up used by Dawkins (1983) required that hens choose between feeding and dustbathing and, as the author commented, the finding that hungry hens are not so motivated as to trade food for litter does not necessarily mean that they are not motivated to dustbathe.

\section{Other litter-related activities}

When discussing whether or not fowl have a specific motivation to dustbathe, it should be remembered that most experiments study whether hens are motivated to get access to litter in general, rather than whether they are motivated to dustbathe in litter. In addition to dustbathing, hens use litter for scratching, pecking and foraging and so access may be important also because it allows the performance of these behaviours. No study has properly addressed the question of a distinct dustbathing motivation. Matthews et al. (1995) calculated different slopes of demand curves for sessions in which hens dustbathed in the litter and sessions where they only pecked and scratched, but no comparison was made of the slopes for the same material between activities.

\section{Plumage condition}

Whether or not hens have the possibility to dustbathe may affect the plumage in two different ways. Firstly, dustbathing itself, as it is important for feather maintenance, will affect the quality of the plumage. Secondly, there is a presumed relationship between dustbathing and the occurrence of feather pecking, an abnormal behaviour which can have detrimental consequences for the plumage. Dustbathing has a short-term effect on feather condition, as reported in the section on function. However, there is little experimental evidence for direct long-term effects, since studies including plumage condition have not been designed to separate a direct effect of prevention of dustbathing from that of a possible increase in feather pecking. In nature, a good plumage is important both for the bird's flight capacity and for thermoregulation. In the wild, deterioration of the plumage could thus be fatal to the bird, but in the protected environment in which domestic hens are kept, a good feather condition is not essential for survival. Nevertheless, it is still possible that having their feathers in bad condition affects birds' well-being.

Feather pecking is an abnormal behaviour known in poultry, in which birds peck at the plumage of other birds and often pull out feathers. Because the pulling out of feathers is painful for the victim and because feather pecking may develop into cannibalism (see McAdie \& Keeling, 2000), it is a welfare problem. In addition, in poultry farming it is also an economical problem, since defeathered birds need to eat more for thermoregulation (Tauson, 1980). Two different hypotheses relate the development of feather pecking with early experiences of litter. Based on his many studies on the ontogeny of dustbathing, Klaus Vestergaard suggested that feather pecking is a consequence of abnormal development of dustbathing behaviour (e g Vestergaard \& Lisborg, 1993; Vestergaard, 1994). According to this hypothesis, birds may become 'imprinted' on the feathers of cagemates as a dustbathing substrate if a suitable substrate is not present during a critical period of dustbathing development. Indeed, it was shown that birds reared with no other dustbathing substrate learnt to dustbathe on feathers (Vestergaard \& Lisborg, 1993; Sanotra et al., 1995). However, access to litter does not only determine whether or not birds can dustbathe but also their possibilities for foraging. According to Blokhuis (1986), feather pecking develops as misdirected ground pecking which is part of the foraging behaviour system. That feather pecking is closely related to foraging behaviour is also supported by other work (Huber-Eicher \& Wechsler, 1997; Bilcík \& Keeling, 2000); however, a recently presented hypothesis suggests feather pecking being related to social exploration (Rodenburg et al., 2004)

Is prevention of dustbathing stressful for the birds? When hens used to dustbathing are prevented from doing so, they express the so-called gakel call indicative of frustration (Zimmerman et al., 2000). A more long-term effect was studied by Vestergaard et al. (1997) by rearing hens until the age of 32-34 months either with or without litter (sand) and thereafter changing treatment, so that wirereared birds were housed on sand and sand-reared birds 


\section{N:I:IBMC}

were housed on wire. Before changing treatment, cortisol levels were similar in birds from the two treatments, but sand-reared birds responded to change of treatment with an increase in cortisol, so that post-change levels were higher than in wire-reared birds. The authors interpreted this as evidence that depriving hens of the possibility of dustbathing is stressful. However, it should be noted that the litter-reared birds in this study had been housed on sand for almost 3 years. The results show that removing litter from birds who have always had access to it is stressful; the data however do not provide information about whether it is stressful for birds to be reared and housed without a dustbathing substrate. Moreover, it may be that the change to housing on a wire floor is in general stressful for reasons other than the deprivation of dustbathing opportunities.

To summarize this section on welfare aspects, whether or not an animal is motivated to perform a behaviour is important if we want to draw conclusions about its welfare. Whereas some studies of motivation indicate that hens are prepared to work for access to litter (Matthews et al, 1993; 1995), others are inconclusive (Widowski \& Duncan, 2000) and yet others have found no evidence of a motivation of dustbathing (Dawkins \& Beardsleay, 1986; Lagadic \& Faure, 1987; Faure, 1991; Faure \& Lagadic, 1994), and it has been suggested that whether or not hens could see litter in the experiments explain these differences in results (Widowski \& Duncan, 2000). Besides the direct effect of thwarting of dustbathing motivation leading to frustration, preventing dustbathing may also affect animal welfare indirectly if, as suggested by Vestergaard (1994), this leads to the development of feather pecking,

\section{Sham dustbathing - a complex example}

Hens which do not have access to litter go through the sequence of dustbathing on the bare floor, a behaviour sometimes referred to as vacuum dustbathing. According to the Lorenzian model of behaviour regulation, a vacuum activity occurs when motivation for a certain behaviour has built up to a sufficiently high level, so that the behaviour is performed in the complete absence of relevant stimuli (see Vestergaard et al., 1999). However, hens 'dustbathing' on wire floors most commonly do so close to the feed trough (Vestergaard, 1981a; Lindberg \& Nicol, 1997). Since it seems as if the birds treat the feed as a dustbathing substrate (Vestergaard et al 1990; 1993; Lindberg \& Nicol, 1997), the term 'sham dustbathing' (as used by van Liere and Wiepkema, 1992 and Lindberg \& Nicol, 1997) is more appropriate. In addition, the notion of sham dustbathing always implies that, irrespective if whether a dust-like stimulus can be seen and / or pecked at, no friable substrate that can penetrate the plumage is accessible for the bird to bathe in.

Development in birds reared without dustbathing substrate As mentioned previously, there are several reports that chicks reared without litter develop a pattern of sham dustbathing rather similar to the dustbathing in litter-reared birds (Vestergaard et al., 1990; Petherick et al., 1995). Vestergaard \& Baranyiova, (1996) reared domestic chicks on a wire floor without litter but gave them regular access to peat and sand to peck in, at the same time as they could sham dustbathe on a glass plate. Access to the pecking substrate elicited sham dustbathing as early as day 10-15 in some chicks but not in all. When the chicks were presented with peat, sand and chicken food as substrates for dustbathing at day $17-18,5$ out of 11 chicks did not dustbathe in any of the substrates, and 9 of 11 chicks were seen sham dustbathing on the wire during observations in the home cage.

Sham dustbathing after long-term deprivation

Once birds have experienced litter, longer deprivation seems to be needed before sham dustbathing develops (Hogan, 1994). Vestergaard et al. (1997) studied the behaviour of hens which had been reared and housed on sand until the age of 32-34 months and were thereafter moved to wire floor. When moved over to wire floor, sandreared birds responded by initially not performing any dustbathing behaviour during the first 20 days. Thereafter short bouts of sham dustbathing were seen, but complete dustbathing sequences were not seen during the 48 days the experiment lasted. Similarly, van Liere and Wiepkema 


\section{N:I:IBMC}

(1992) found that birds previously housed on litter (although reared without litter) responded to litter deprivation with an initial disappearance of dustbathing behaviour. However, sham dustbathing increased over the period of litter deprivation, so that by 21 weeks of deprivation birds showed amounts of sham dustbathing comparable to the dustbathing of control hens housed on litter. When these deprived birds were given access to litter after 23 weeks of deprivation, most hens dustbathed in the sand but 5 out of 20 continued to show sham dustbathing. We have confirmed this finding of continued sham dustbathing in the presence of litter by showing that some individuals in a group of hens deprived of litter for 12 weeks sham dustbathed in their habitual place even after they had been given free access to litter in a different place in the pen (Olsson et al, 2002a). In younger birds, sham dustbathing seems to appear after shorter deprivation times than in adult birds, as indicated by the finding of Petherick et al., (1995) that the majority of 12-week-old pullets sham dustbathed after only 21 days of deprivation when peat was presented under the cage. This is consistent with Hogan and Van Boxel's (1993) finding that young birds dustbathe more often than adult birds.

Van Liere and Wiepkema (1992) deprived birds of litter for a period of 30 weeks, and during 3-week periods within this litter deprivation also prevented sham dustbathing. Prevention resulted in a rebound of sham dustbathing when the behaviour was again made possible. Although this suggests that sham dustbathing is rewarding in itself, two later studies have failed to show that performing sham dustbathing reduces the motivation to dustbathe in litter. Lindberg (1999) kept adult hens on either a wire floor or a litter floor for 6 weeks and registered their performance of dustbathing behaviour (sham or in litter). For testing, the hens were moved to a pen with litter 4 or 24 hours after a dustbathing bout in the home pen, and their dustbathing in litter was recorded. Wire-kept hens dustbathed irrespective of the time since last sham dustbathing, indicating that sham dustbathing did not reduce the motivation to dustbathe in litter. Likewise, we have not been able to demonstrate an effect of previous sham dustbathing on dustbathing in litter. After eight weeks of initial litter deprivation, hens were prevented from both litter dustbathing and sham dustbathing in their home pen. At 2week intervals the hens were observed in a situation where they were first given one of three treatments: 1) wire floor with horizontal rods preventing sham dustbathing, 2) wire floor allowing sham dustbathing and 3) full litter access, and thereafter allowed to dustbathe in litter. In this situation, where hens were given access to litter at 2-week intervals, very few hens sham dustbathed, and sham dustbathing did not reduce subsequent dustbathing in litter (Olsson et al, 2002a).

In summary, sham dustbathing appears after long-term deprivation but there is little evidence that its performance reduces motivation to dustbathe in litter.

Sham dustbathing in furnished cages Furnished cages for laying hens are equipped with a dustbath in order to satisfy hens' motivation to dustbathe. Although some experimenters report all dustbathing taking place in the dustbaths (Appleby \& Hughes, 1995), we and others have found that hens sham dustbathe on the cage floor even in these furnished cages. Lindberg and Nicol (1997) found that about two thirds of the dustbathing bouts were on the cage floor in furnished cages with a dustbath when there was free access to the dustbath, whereas limiting access to the dustbath in the morning hours resulted in as much as $92 \%$ of the dustbathing being sham dustbathing. There was no difference in frequency nor duration of dustbathing bouts between cages with and without a dustbath, but sham dustbathing bouts on the wire floor were less than half the duration of dustbathing bouts in the dustbath. Sham dustbathing almost always took place at the feed trough and Lindberg and Nicol (1997) suggested that the performance of sham dustbathing is satisfying enough to reduce the motivation for dustbathing, given that the hens have access to a loose substrate for pecking and bill-raking while sham dustbathing. However, as stated previously, later experimental studies have failed to show that sham dustbathing reduces the motivation to bathe in litter 


\section{N:I:IBMC}

(Lindberg, 1999; Olsson et al., 2002a). An alternative hypothesis could be that birds sham dustbathe on the wire floor as a consequence of social competition for the limited space in the dustbath, when several birds are motivated to dustbathe at the same time. While testing this hypothesis, we however found that sham dustbathing in furnished cages rarely coincided with the dustbath being occupied (Olsson \& Keeling, 2002), suggesting that competition for the dustbath is an unlikely explanation.

Birds housed in furnished cages are generally reared in conventional cages without litter. In combination with the finding that both young (Vestergaard \& Baranyiova, 1996) and adult (van Liere \& Siard, 1991) birds without prior experience of litter continue to sham dustbathe also in the presence of litter, we have suggested that the sham dustbathing in furnished cages may be a consequence of rearing without litter (Olsson \& Keeling, 2002).

In a series of experiments, Merrill and co-workers investigated the possibility of providing hens with non-litter substrates which would elicit dustbathing behaviour and which would give more feedback (and consequently be more satisfactory) than sham dustbathing on the wire floor. They found that no non-litter material elicited the full sequence of dustbathing behaviour; however birds on a brushy surface (such as different types of artificial turf) dustbathed significantly more than on a wire floor and in some cases with a total duration similar to dustbathing in litter (Merrill et al., in press). When given the choice between a cage where the floor was covered with perforated Astro-turf and a cage with conventional wire floor, the majority of birds dustbathed on the Astro-turf floor (Merrill et al., submitted)

In summary, the fact that hens in battery cages show sham dustbathing on the wire floor has been taken as an indication for a strong internal dustbathing motivation. This seems to be the case, when hens deprived of litter for long periods start to show sham dustbathing even without any salient dusty stimuli (van (Liere \& Wiepkema, 1992); Olsson et al., 2002a). But the phenomenon of sham dustbathing in hens reared without litter seems to be rather different, being more similar to the normal dustbathing behaviour of hens reared with litter (Vestergaard et al., 1990): Sham dustbathing in hens reared without litter is often seen near the feed trough, where the birds can reach to peck and billrake in the feed (Lindberg \& Nicol, 1997; Olsson \& Keeling, 2002). Hogan (1994) suggested that development of the full dustbathing mechanism is dependent on experience establishing dust recognition. For birds reared in cages without litter, their only experience will be that of sham dustbathing while bill-raking in the feed. As a consequence, this type of sham dustbathing will be the dustbathing behaviour which these hens develop. Whether or not this behaviour is satisfactory from the welfare point of view remains to be established.

\section{The Tinbergian framework - was it useful?}

Using the Tinbergian approach as the framework for this review, we have divided studies of dustbathing behaviour in four different categories, according to whether they mainly address questions of ontogeny, phylogeny, function or causation. Although reality is never as neat and categorical as the theoretical framework one tries to apply upon it, and some studies address several questions simultaneously, we nevertheless found the Tinbergian four questions useful as a systematic approach to a series of diverse and different studies of one and the same behaviour system.

To summarize the reviewed studies, we conclude that there is considerable knowledge about how dustbathing behaviour develops in different situation, with and without the presence of dustbathing substrates. A number of important causation mechanisms controlling the initiation and performance of dustbathing behaviour have also been identified. Much less is known about phylogeny and function: we know that several species show dustbathing behaviour and that the performance of the behaviour improves the insulation capacity of the plumage, but other aspects have not been studied. 


\section{N:I:IBMC}

The obvious bias towards studies of causation has to do with the animal welfare approach that most studies have had and the central importance of research into motivation for drawing conclusions about animal welfare (see Duncan, 1995). Research which can provide answers to animal welfare questions remains a high priority in present society with its increasing concern for the well-being of non-human animals and continued development of legal instruments to protect them. Although it may seem that what is missing to give a full understanding of dustbathing behaviour would be more studies into phylogeny and function, such studies are not the most likely to provide answers to the important questions about the relation between dustbathing behaviour and hen welfare in commercial systems. Neither will they be provided by more attempts to answer the causational "Why?". Rather, we propose that at the present level of knowledge answers to questions about welfare are most likely to come from a combination of different approaches.

We would also like to draw the attention to a different point addressed by Tinbergen (1963), namely that of the balance between observational and experimental approaches to the study of behaviour. There has been an obvious bias towards experimental studies of dustbathing behaviour, and an understanding of the relation between bird welfare and dustbathing behaviour may very well benefit from more observational studies in the captive environments in which most fowl are kept. Combining ontogeny and causation in addressing the question of how dustbathing motivation is affected by early experience is one of the approaches that seems particularly pertinent at this moment, and the issue of sham dustbathing and use of dustbaths in furnished cages can serve as an example of this. Several studies show that birds in such cages do not use the dustbaths as much as expected and that considerable sham dustbathing is still seen. In the European Union the installation of conventional battery cages for laying hens has recently become illegal and some farmers are investing in furnished cages as one of the alternatives. If hens do not use the dustbaths in such cages because the hens do not have the appropriate experience, because they are not motivated to dustbathe or because of the design of the dustbath, then the intended welfare benefits of the legislation will not be realized by the hens.

\section{References}

Appleby, M.C., Hughes, B.O. 1995. The Edinburgh Modified Cage for laying hens. British Poultry Science 36, 707-718.

Bilcík, B., Keeling, L.J. 2000. Relationship between feather pecking and ground pecking in laying hens and the effect of group size. Applied Animal Behaviour Science 68, 55-66

Blokhuis, H.J. 1986. Feather-pecking in poultry: its relation with ground pecking. Applied Animal Behaviour Science 26, 63-67.

Blokhuis, H.J. 1989. The development and causation of feather pecking in the domestic fowl. Thesis. Spelderholt Centre for Poultry Research and Extension, The Netherlands.

Borchelt, P.L., Eyer, J., McHenry Jr, D.S. 1973. Dustbathing in Bobwhite quail (Colinus virginianus) as a function of dust deprivation. Behavioural Biology 8, 109-114.

Borchelt, P.L., Duncan, L. 1974. Dustbathing and feather lipids in Bobwhite quail (Colinus virginianus). Condor 76, 471-472.

Borchelt, P.L., Overmann, S.R. 1975. Development of dustbathing in bobwhite quail.II Effects of early pecking experiences. Developmental Psychobiology 8, 417-423.

Brett, W.J., Kruse, M. 1967. Development of dusting pattern in young quail (Coturnix coturnix japonica). Proc. Ind. Acad. Sci. 75, 282.

Dawkins, M. 1981. Priorities in the cage size and flooring preferences of domestic hens. British Poultry Science 22, 255-263. 


\section{: :E: IBMC}

Dawkins, M.S. 1983. Battery hens name their price: Consumer demand theory and the measurement of ethological "needs". Animal Behaviour 31, 1195-1205.

Dawkins, M.S. 1990. From an animal's point of view: Motivation, fitness and animal welfare. Behavioural and Brain Sciences 13, 1-61.

Dawkins, M. S. 1998. Evolution and animal welfare. The Quarterly Review of Biology 73, 305-328.

Dawkins, M.S., Beardsley, T. 1986. Reinforcing properties of access to litter in hens. Applied Animal Behaviour Science 15, 351-64.

Duncan, I.J.H. 1995. D.G.M. Wood-Gush Memorial Lecture: An applied ethologist looks at the question "Why?". Applied Animal Behaviour Science 44, 205-217.

Duncan, I.J.H., Widowski, Tina M., Malleau, A.E., Lindberg, A.C., Petherick, J.C. 1998. External factors and causation of dustbathing in domestic hens. Behavioural Processes 43 , 219-228.

Faure J.M. 1991 Rearing conditions and needs for space and litter in laying hens. Applied Animal Behaviour Science 31, 111-117.

Faure, J.M. \& Lagadic, H. 1994 Elasticity of demand for food and sand in laying hens subjected to variable wind speed. Applied Animal Behaviour Science 42, 49-59.

Fraser, D. , Duncan, I.J.H. 1998. 'Pleasures', 'pains' and animal welfare. Towards a natural history of affect. Animal Welfare 7, 383-396.

Gerken, M., Petersen, J. 1987. Bidirectional selection for dustbathing activity in Japanese quail (Coturnix coturnix japonica). British Poultry Science 28, 23-37.

Gerken, M., Bamberg, H., Petersen, J. 1988. Studies of the relationship between fear-related responses and production traits in Japanese quail (Coturnix coturnix japonica) bidirectionally selected for dustbathing activity. Poultry Science 67, 1363-1371.

Gunnarsson, S., Matthews, L.R, Foster, T.M., Temple, W. 2000. The demand for straw and feathers as litter substrates by laying hens. Applied Animal Behaviour Science 65, 321-330.

Hogan J.A. 1994. Structure and development of behavior systems. Psychonomic Bulletin and Review 1, 439-450.

Hogan, J.A., Honrado, G.L., Vestergaard, K. 1991.

Development of a behavior system: Dustbathing in the Burmese red junglefowl (Gallus gallus spadiceus): Internal factors. Journal of Comparative Psychology 105, 269-273.

Hogan, J.A., Van Boxel, F. 1993. Causal factors controlling dustbathing in Burmese red junglefowl: some results and a model. Animal Behaviour 46, 627-633.

Huber-Eicher, B, Wechsler, B. 1997. Feather pecking in domestic chicks: Its relation to dustbathing and foraging. Animal Behaviour 54, 757-768.

Johnsen, P.F., Vestergaard, K.S., Nørgaard-Nielsen, G. 1998. Influence of early rearing conditions on the development of feather pecking and cannibalism in domestic fowl. Applied Animal Behaviour Science 60, 25 41.

Kruijt, J.P. 1964. Ontogeny of social behaviour in Burmese red junglefowl (Gallus gallus spadiceus). Behaviour, Supplementum 12, 201 pp.

Lagadic, H., Faure, J.M. 1987 Preferences of domestic hens for cage size and floor types as measured by operant conditioning. Applied Animal Behaviour Science 19, 147155.

Larsen B.H., Vestergaard, K.S., Hogan, J.A. 2000.

Development of dustbathing behaviour sequences in the 


\section{N:I:IBMC}

domestic fowl: the significance of functional experience.

Developmental Psychobiology 37, 5-12.

van Liere, D.W. 1991. Function and organization of dustbathing in laying hens. Wageningen Agricultural University, Wageningen, The Netherlands.

van Liere, D.W. 1992a. Dustbathing as related to proximal and distal feather lipids in laying hens. Behavioural Processes 26 177-188.

van Liere, D.W. 1992b. The significance of fowls' bathing in dust. Animal Welfare 1, 187-202.

van Liere, D.W., Bokma, S. 1991. Short-term feather maintenance as a function of dustbathing in laying hens. In: van Liere, D.W. 1991. Function and organization of dustbathing in laying hens. Wageningen Agricultural University, Wageningen, The Netherlands.

van Liere, D.W., Siard, N. 1991. The experience of litter and subsequent selection of bathing substrate in laying hens. In: van Liere, D.W. 1991. Function and organization of dustbathing in laying hens. Wageningen Agricultural University, Wageningen, The Netherlands.

van Liere, D.W., Wiepkema, P.R. 1992. Effects of long-term deprivation of sand on dustbathing behaviour in laying hens. Animal Behaviour 43, 549-558.

Lindberg, A.C., Nicol, C.J. 1997. Dustbathing in modified battery cages: Is sham dustbathing an adequate substitute? Applied Animal Behaviour Science 55, 113-128.

Lindberg, A.C. 1999. Effects of vacuum and real dustbathing bouts on dustbathing motivation in domestic hens. In: Proceedings of the $33^{\text {rd }}$ Congress of the International Society for Applied Ethology. Lillehammer. Norway.

Lundberg A.S., Keeling L.J. 2003. Social effects on dustbathing behaviour in laying hens: using video images to investigate effect of rank. Applied Animal Behaviour Science 81, 43-57

Matthews, L.R., Temple, W., Foster, T.M., McAdie, T.M. 1993. Quantifying the environmental requirements of layer hens by behavioural demand functions. . In: Proceedings International Congress on Applied Ethology. Berlin,

Germany

Matthews, L.R., Temple, W., Foster, T.M.; Walker, J., McAdie, T.M. 1995. Comparison of the demand for dustbathing substrates by layer hens. In: Proceedings of the $29^{\text {th }}$ Congress of the International Society for Applied Ethology. Exeter, UK.

Matthews, L.R., Walker, J., Foster, T.M. \& Temple, W. 1998. Influence of reward magnitude on elasticity of demand for dustbathing in hens. In: Proceedings of the 32nd Congress of the International Society for Applied Ethology. Clermont-Ferrand, France.

McAdie, T.M., Keeling, L.J. 2000. Effect of manipulating feathers of laying hens on the incidence of feather pecking and cannibalism. Applied Animal Behaviour Science 68, 215-229.

Merrill, R.J.N., Nicol, C.J. The effects of novel floorings on dustbathing, pecking and scratching behaviour of caged hens Animal Welfare. In press.

Merrill, R.J.N., Cooper, J.J., Albentosa, M.C., C.J. Nicol. Preferences of laying hens for perforated Astroturf over conventional wire as a dustbathing substrate in enriched cages. Submitted

Nicol, C.J., Guilford, T. 1991. Exploratory activity as a measure of motivation in deprived hens. Animal Behaviour $41,333-341$

Nicol, C.J., Lindberg, A.C., Phillips, A.J., Pope, S.J., Wilkins, L.J., Green, L.E. 2001. Influence of prior exposure to wood shavings on feather pecking, dustbathing and 


\section{:I:-IBMC}

foraging in adult laying hens. Applied Animal Behaviour Science 73, 141-155.

Nørgaard-Nielsen, G. 1997. Dustbathing and feather pecking in domestic chicks reared with and without access to sand. Applied Animal Behaviour Science 52, 99-108.

Nørgaard-Nielsen, G., Vestergaard, K. 1981. Dustbathing behaviour of uropygial gland extirpated domestic hens: Effects of dust deprivation. Acta Veterinariæ Scandinavica 22, 118-128.

Olsson, I.A.S., Keeling, L J. 2002. No effect of social competition on sham dustbathing in furnished cages for laying hens. Acta Agriculturae Scandinavica (Sect A Animal Science) 52, 253-256.

Olsson, I. A. S., Keeling, L. J., Duncan, I.J.H. 2002a. Why do hens sham dustbathe when they have litter? Applied Animal Behaviour Science 76, 53-64.

Olsson I.A.S., Duncan I.J.H., Keeling L.J., Widowski T.M. 2002b. How important is social facilitation for dustbathing motivation in laying hens? Applied Animal Behaviour Science 79, 285-297.

Petherick, J.C., Duncan, I.J.H. 1989. The behaviour of young domestic fowl directed towards different substrates. British Poultry Science 30, 229-238.

Petherick, J.C., Rushen, J. 1997. In: Appleby, M.C. \& Hughes, B.O. (eds), Animal Welfare. pp 89-105. Oxon: CAB International.

Petherick, J C, Waddington, D, Duncan, I J H. 1990. Learning to get access to a foraging and dustbathing substrate by domestic fowl: is 'out of sight out of mind'? Behavioural Processes 22, 213-226.

Petherick, J.C., Seawright, E., Waddington, D. 1993. Influence of motivational state on choice of food or a dustbathing/foraging substrate by domestic hens.

Behavioural Processes 28, 209-220.

Petherick, J.C., Seawright, E., Waddington, D., Duncan, I.J.H., Murphy, L.B. 1995. The role of perception in the causation of dustbathing behaviour in domestic fowl. Animal Behaviour 49, 1521-1530.

Rodenburg, T.B., van Hierden, Y.M., Buitenhuis, A.J., Riedstra, B., Koene, P., Korte, S.M., van der Poel, J.J., Groothuis, T.G.G. and Blokhuis, H.J. 2004. Feather pecking in laying hens: new insights and directions for research. Applied Animal Behaviour Science 86, 291-298.

Sambraus, H.H. 1994. Comfort behaviour of the African ostrich (Struthio-camelus). Deutsche Tierärtzliche Wochenschrift 101, 307-308.

Sandilands, V., Savory, J. and Powell, P. 2004. Preen gland function in layer fowls: factors affecting morphology and feather lipid levels. Comparative Biochemistry and Physiology Part A 137, 217-225.

Sanotra, G.S., Vestergaard, K.S., Agger, J.F., Lawson, L.G. 1995. The relative preferences for feathers, straw, woodshavings and sand for dustbathing, pecking and scratching in domestic chicks. Applied Animal Behaviour Science 43, 263-277.

Simmons, K.E.L 1964. Feather maintenance. In: Thompson (ed) A New Dictionary of Birds. pp 187-286. New York: McGraw-Hill.

Sherwin C.M., Kelland A. 1998. Time-budgets, comfort behaviours and injurious pecking of turkeys housed in pairs. British Poultry Science 39, 325-332

Shields, S.J., Garner, J.P. \& Mench, J.A. 2004. Dustbathing by broiler chickens: a comparison of preference for four different substrates. Applied Animal Behaviour Science 86, 291-298. 


\section{I:IIIIMC}

Tauson, R. 1980. Influence of plumage condition on the hen's feed requirement. Swedish Journal of Agricultural Research 10, 35-39.

Tinbergen, N. 1963. On aims and methods of ethology. Zeithschrift Tierpsychologie 20, 410-433.

Vestergaard, K.1981a. Behavioural and physiological studies of hens on wire floor and in deep litter pens. Tierhaltung 12, 115-132.

Vestergaard, K.1981b. The well-being of the caged hen an analysis based on the normal behaviour of fowls.

Tierhaltung 12, 145-167.

Vestergaard, K. 1982. Dust-bathing in the domestic fowl diurnal rhythm and dust deprivation. Applied Animal Ethology 8, 487-495.

Vestergaard, K.S. 1994. Dustbathing and its relation to feather pecking in the fowl: Motivational and developmental aspects. PhD thesis. 150 pp. Department of Animal Science and Animal Health. The Royal Veterinary and Agricultural University. Copenhagen, Denmark.

Vestergaard, K., Hogan, J.A. 1992. The development of a behavior system: Dustbathing in the Burmese Red Junglefowl III. Effects of experience on stimulus preference. Behaviour 121, 215-230.

Vestergaard, K., Lisborg, L. 1993. A model of feather pecking development which relates to dustbathing in the fowl. Behaviour 126, 89-105.

Vestergaard, K.S., Baranyiova, E. 1996. Pecking and scratching in the development of dust perception in young chicks. Acta Veterinaria Brno 65, 133-142.

Vestergaard, K., Hogan, J.A., Kruijt, J.P. 1990. The development of a behavior system: Dustbathing in the Burmese Red Junglefowl I. The influence of the rearing environment on the organization of dustbathing. Behaviour $112,99-115$

Vestergaard, K.S., Kruijt, J.P., Hogan, J.A. 1993. Feather pecking and chronic fear in groups of red junglefowl: their relations to dustbathing, rearing environment and social status. Animal Behaviour 45, 1127-1140.

Vestergaard, K.S., Skadhauge, E., Lawson, L.G. 1997. The stress of not being able to perform dustbathing in laying hens. Physiology and Behavior 62, 413-419.

Vestergaard, K.S., Damm, B.I., Abbott, U.K., Blidsøe, M. 1999. Regulation of dustbathing in feathered and featherless domestic chicks: the Lorenzian model revisited. Animal Behaviour 58, 1017-1025.

Widowski, T.M., Duncan I.J.H. 2000. Working for a dustbath: Are hens increasing pleasure rather than relieving suffering? Applied Animal Behaviour Science 68, 39-53.

Zimmerman P.H., Koene P., van Hooff J.A.R.A.M. 2000 Thwarting of behaviour in different contexts and the gakelcall in the laying hen. Applied Animal Behaviour Science 69, 255-264. 